\title{
Study on Reforms in College Volleyball Teaching
}

\author{
Xuegong Du \\ College of Physical Education, Yan'an University, Yanan Shaanxi, 716000, China
}

Keywords: Sports education college, Volleyball teaching, Reform, Reasonable suggestions

\begin{abstract}
Colleges, which always shoulder the significant responsibility for delivering talents for the country and society, are the main places for cultivating talents. College sports education, an important part of education in China, also plays an irreplaceable role. College volleyball course is one of the sports projects set in colleges. With the deepening of reforms in educational system, a series of reforms have also been carried out in college volleyball teaching. However, the process of reform is less than satisfactory. On this basis, this paper analyzes the current situation of college volleyball teaching, states the significance of reforms in college volleyball teaching, points out main factors influencing reforms in college volleyball teaching, and proposes reasonable suggestions for deepening reforms in college volleyball teaching.
\end{abstract}

\section{Introduction}

Dating from 1895, the volleyball has become one of the sports courses in general institutes of higher education after development for over 100 years. Since volleyball integrates fitness nature, entertainment, competitive nature and ornamental value, volleyball is deeply loved and recognized by teachers and students ${ }^{[1]}$. However, the current situation of volleyball teaching in colleges of China is not optimistic, and there are still some problems after reforms and innovations. This paper discuss from this, in the hope of searching for a new way for reforms in college volleyball teaching so as to offer some advisory opinions for sports teachers in colleges to improve volleyball teaching.

\section{Current situation of college volleyball teaching in our country}

\section{Ambiguous teaching objectives}

A teaching objective, which means the expected learning result or standard achieved by students after teachers' teaching, points out the direction of designing teaching activities by teachers, and meanwhile is also an important basis for teaching evaluation ${ }^{[2]}$. Therefore, teaching objectives must be clear and ambiguous teaching objectives are not allowed. However, teaching objectives are still ambiguous in volleyball teaching in many colleges of our country. Many teachers teach according to their subjective consciousness or some teachers set too high or too low teaching objectives, resulting in unsatisfactory volleyball teaching effects in colleges and failure to sufficiently meet students' learning needs.

\section{Non-abundant teaching content}

As influenced by traditional teaching concepts, some college sports teachers fail to design sufficiently rich teaching contents, overemphasize the competitive nature of volleyball in the teaching process, neglect the ornamental value and entertainment value of volleyball, and don't consider improving students' comprehensive abilities as one of their teaching concepts. All of them influence the propulsion of quality-oriented education in our country to a certain extent ${ }^{[3]}$. Besides, with the development of society, people face growing living and working pressures, and playing sports is the only effective way to reduce pressure. Therefore, college sports teachers must deeply understand this, pay attention to the fitness nature of volleyball and reduce students' learning pressure by playing volleyball.

\section{Traditional and conservative teaching patterns and methods}

As for the college volleyball teaching patterns and methods, there are still traditional and conservative teaching patterns and methods. A part of sports teachers use the cramming teaching method, and blindly teach volleyball knowledge and volleyball skills to students so that students can 
only learn routinely. Although some teaching effects (only few effects) can be achieved through such teaching patterns and methods, such patterns and methods are likely to cause students' opinion upon volleyball and cause them to have an attitude of exclusion toward volleyball course due to their lack of innovation. Actually, volleyball teaching is supposed to be a dynamic process. In practical teaching, teachers shall timely communicate and interact with students and timely improve their teaching methods according students' learning feedback. Meanwhile, teachers should also fully respect students' position of dominant role, and actively create a favorable learning environment for students. Only in this way can teachers yield twice the result with half the effort in volleyball teaching. This teaching pattern and method are most scientific and reasonable.

\section{Simple teaching evaluation}

The volleyball teaching evaluation is too simple. Usually, students are assessed through their achievement tests and grasping of sports skills. That the quantitative indicators for performance appraisal are used as the key points of assessment goes against teachers commanding the practical and dynamic learning conditions of students. For instance, some students may not perform well in separate training but perform extremely outstandingly in teams. Therefore, such universal assessment and evaluation form is too one-sided and even will dispel students' enthusiasm in learning volleyball.

\section{Teachers' quality needs improving}

Since teachers are the organizers and executors of teaching activities, teachers' professional ability and quality directly influence students' learning effects ${ }^{[4]}$. China's education system had just started, and both teaching training system and post-holding system are not perfect now, so volleyball teachers' professional ability and quality are not high. In addition, volleyball, which is introduced from western countries, does not exist for a long time in China's sports education, sports teachers' volleyball teaching cannot meet the current teaching needs. Thus, college sports teachers' quality needs improving.

\section{Necessity of reforms in college volleyball teaching}

\section{Cultivate students' lifelong sports consciousness}

Reforming college volleyball teaching helps to implement the 'goal of lifelong sports' and then to cultivate students' lifelong sports consciousness. The sports curriculum setting aims at helping students to obtain better development and promoting students' physical and psychological health. For this reason, it is required to help students to build the consciousness of 'lifelong sports'. Reforms and innovations in college volleyball teaching can improve students' interest in learning volleyball, make students recognize volleyball correctly, and thus help them to establish the goal of 'lifelong sports'.

\section{Help students to better command volleyball skills}

Reforms in volleyball teaching cover many contents including the volleyball teaching goals, volleyball teaching patterns, volleyball teaching means, methods and evaluation etc., all of which aim at thoroughly enhance the quality of volleyball teaching. The leading 'beneficiaries' in the series of reforms are students. The whole reform process takes students as the starting point and foothold so that students can better grasp volleyball skills to lay a solid foundation for their future physical exercise and volleyball playing.

\section{Enhance students' comprehensive quality}

Volleyball has numerous advantages. Playing volleyball not only can improve students' speed, endurance, leaping ability, flexibility and other physical qualities but also cultivate students' team collaboration ability and improve their sense of group honor. Furthermore, apart from the competitive nature, volleyball also has entertainment and ornamental values. Reforms in volleyball teaching can improve students' interest in learning volleyball, make them actively to learn volleyball sports and participate in volleyball sports, and thus achieve the goal of enhancing students' comprehensive quality. 


\section{Key factors influencing reforms in volleyball teaching}

\section{Influences of relevant policies and regulations}

Policies and regulations, which greatly affect reforms in college volleyball teaching, are not only the administrative means and manifestation patterns for governments to exercise the official power, but also the guiding thinking principles leading colleges' volleyball teaching. Due to their enforceability, policies and regulations become the leading factor influencing reforms in volleyball teaching. Lately, our country carried out the Guidance Outlines for Sports Education in Nationwide Regular Institutions of Higher Education, where there are still some problems due to the imperfect specific policies and regulations. Besides, volleyball teaching reforms cannot be comprehensively, effectively and successfully carried out now.

\section{Resource factor}

The resource factor, which is also one of the significant factors influencing reforms in volleyball teaching in our country, includes human resource, material resource and financial resource. The human resource mainly refers to sports teachers in colleges. Without high-level teacher teams, reforms in volleyball teaching are not professional and the teaching reform orientation will deflect. The material resource refers to equipment, places, teaching tools etc. With the support of material resource, reforms in volleyball teaching are tantamount to 'engaging in idle theorizing' and cannot be effectively implemented. The financial resource, which refers to the national educational department and colleges' funding intensity in volleyball teaching in colleges, also influences the human resource and material resource to a certain degree, so, in a manner of speaking, the financial resource is the leading resource factor influencing reforms in volleyball teaching.

\section{Study on teaching reforms}

The study on volleyball teaching is the important premise of reforms in volleyball teaching. To smoothly carry out reforms in volleyball teaching and make remarkable improvements, it is required to conduct systematic, comprehensive and professional studies on volleyball teaching. Although numerous teaching researchers carried out relevant studies on volleyball teaching and put forward relevant suggestions about teaching reforms, their study results fail to hold the post of leading volleyball reforms and development due to the relatively lagging studies concerned. For example, most teaching researchers mainly focused on how to introduce volleyball to colleges, which was a historical problem. Nowadays, the reforming emphasis of volleyball teaching shall be placed in practical teaching, studies on diversified teaching patterns and evaluations; improving the quality of volleyball teaching on former basis should be the top priority of volleyball teachers now. Therefore, the current studies on reforms in volleyball teaching are divorced from reality, and thus this has become one of the significant factors which influence the reforms in volleyball teaching in colleges.

\section{Suggestions about deepening reforms in college volleyball teaching}

\section{Clearly building teaching objectives}

Clearly building volleyball teaching objectives is the antecedent condition for reforms in volleyball teaching ${ }^{[5]}$. For this reason, college sports teachers must take a new look at volleyball teaching, form correct volleyball teaching objectives, meanwhile, change the traditional teaching concepts, combine the concept of 'quality education', and change cultivating students' volleyball skills into cultivating their comprehensive quality. Only in this way can college sports teachers grab key teaching points, optimize teaching forms and improve teaching quality in their future teaching process.

\section{Enrich teaching contents}

Teachers should continuously enrich teaching contents, properly introduce beach volleyball, soft ball and other entertainment volleyball projects, change the traditional 'competitive volleyball' teaching, no longer take technical teaching as the main content, fully respect students' position of dominant role in teaching, organically integrate cultivating students' volleyball skills with meeting their learning needs, and avoid blindly instilling theoretical knowledge about volleyball to students so 
that students can deeply experience the joys brought by playing volleyball when participating in volleyball and thus will be more enthusiastic with volleyball.

\section{Innovate teaching methods}

Teaching methods directly influence the teachers' teaching efficiency, so college sports teachers must ceaselessly create teaching methods to improve teaching quality. Nowadays, human beings has stepped into the well-developed information age and multi-media technology has been extremely widely applied, so teachers can utilize multi-media software in volleyball teaching to play volleyball games for students. Students can learn relevant volleyball skills and further learn knowledge about volleyball better through observing the volleyball players' standard movements and their handling methods in each link of a volleyball game; or according to the problem of 'girls' low serve over-net rate', teachers should properly shorten the girls' volleyball practice court for 1 to 3 meters and then gradually recover it to normal. Such progressive method can improve their teaching efficiency, keep students' learning enthusiasm, and avoid reducing students' learning enthusiasm due to incorrect teaching methods.

\section{Improve teaching patterns}

College sports teachers should improve their teaching patterns, which shall be dominated by 'theories + practices' instead of cramming teaching and blind teaching of knowledge. For instance, in the course of volleyball theories, ask students to conduct practical operations; in the volleyball practice course, alternately introduce volleyball-related theoretical knowledge or competition rules. In this way, students can better command volleyball skills and can understand the knowledge about volleyball more deeply.

\section{Establish a diversified evaluation mechanism}

Establish a diversified teaching evaluation system rather than only evaluate students' academic records. From the objective perspective, based on students' knowledge about skills, sports cognitive level, attitude towards learning sports, professional sports quality and many other aspects, teachers shall combine process evaluation with result evaluation so as to guarantee the scientificity and preciseness of evaluation system. Meanwhile, teachers can also include students' classroom performance and their active degree of participating in volleyball sports in the final examination results to help them develop a good learning habit and an active learning attitude.

\section{Strengthen the construction of teaching staff}

Continuously strengthen the construction of teaching staff and improve the teaching level of college sports teachers. As knowledge transmitters, teachers are key figures influencing the volleyball teaching efficiency, so the reforms in volleyball teaching can be carried out smoothly only by improving teachers' professional ability and quality. At first, colleges should maintain a strict standard for recruiting sports teachers, and guarantee that each sports teacher has the post-holding certificate or a certain level of educational background. Secondly, regularly convene academic exchange conferences to provide teachers with platforms for communications so that they can share their teaching experience and finally they all can learn from others' strong points to offset their weakness to gradually improve the teaching patterns as well as teaching quality.

\section{Conclusion}

To sum up, the current situation of college volleyball teaching in our country is not optimistic. Teaching reforms carried out fail to achieve the ideal effect due to the influence of numerous objective factors. Thus, this paper analyzes the factors which influence reforms in college volleyball teaching, proposes strategies for further deepening teaching strategies in the hope of helping reforms in college volleyball teaching to break through bottleneck so that volleyball teaching can develop its maximum value and better serve every student. 


\section{References}

[1] Liu Ji'an. Study on Current Situation of College Volleyball Teaching and Countermeasures. Contemporary Sports Technology, 2013,3(33):105,107.

[2] Zhou Songqing. Study on Reforms in College Volleyball Teaching under Visual Threshold of Sunshine Sports. Journal of Higher Education, 2015(4):29-30.

[3] Dai Ruilei. Study on Reforming Experiments in College Volleyball Teaching under National Student Physical Health Standard. Journal of Jining University, 2009, 30(3):56-58.

[4] Zhou Hao. Study on Current Situation of College Volleyball Teaching and Countermeasures. Journal of Jilin Teachers Institute of Engineering and Technology, 2009, 25 (8): 49-50.

[5] Liu Xin and Huang Shihua. Thought on Reforms in College Volleyball Teaching. Journal of Chongqing University of Science \& Technology (edition of social science), 2015(3): 122-123. 